\title{
JUSTIFYING IMPRISONMENT: ON THE OPTIMALITY OF EXCESSIVELY COSTLY PUNISHMENT
}

\author{
Abraham L. Wickelgren ${ }^{*}$ \\ Federal Trade Commission \\ awickelgren@ftc.gov \\ May 2002
}

\begin{abstract}
The criminal punishment literature has focused on justifying non-maximal punishments and the use of non-monetary sanctions. It has not addressed why imprisonment, rather than cheaper forms of corporal punishment, should be the dominant type of non-monetary sanctions. David Friedman (1999) recently hypothesized that, because convicts lack political influence, it is desirable to make punishment more costly than necessary to prevent policy makers from excessively punishing convicts. This paper explicitly models this hypothesis and uses simulations to determine under what circumstances this hypothesis justifies using imprisonment rather than cheaper non-monetary sanctions.
\end{abstract}

\footnotetext{
* I am grateful to Matt Ellman, Steve Levitt, and Joel Schrag for comments. The views expressed in this paper are those of the author and do not necessarily represent the views of the Federal Trade Commission or any individual Commissioner. All errors are my own.
} 


\section{Introduction}

In Gary Becker's (1968) seminal article on the economics of crime and punishment, he argued that the most efficient way to deter criminals was through meting out very large punishments with very small probability. Since this leads to some paradoxical results (billion dollar fines for jaywalking, enforced once a millennium) and does not reflect the form of actual punishments, many economists have refined Becker's theory. Much of this literature aims to explain why we do not see maximal punishments and very small detection rates (Polinsky and Shavell 1979; Posner 1985; Shavell 1987a; Malik 1990; Miceli 1990; Miceli 1991; Polinsky and Shavell 2000b; Garoupa 2001), as Becker's theory suggests is optimal, and why fines do not play the large role in punishing criminals that Becker argues they should (Polinsky and Shavell 1984; Chu and Jiang 1993; Levitt 1997). See Garoupa (1997) and Polinsky and Shavell (2000a) for excellent surveys of this literature. While these refinements do provide convincing justifications for why we do not always use maximal punishments and why we use non-monetary sanctions, they do not justify why imprisonment should be (by far) the dominant form of non-monetary sanctions. Thus, this paper is not about the choice between fines and non-monetary sanctions. Instead, it investigates the optimality of imprisonment in cases where non-monetary sanctions, in some form, are optimal (for the reasons given by the authors listed above).

From the standpoint of deterrence theory, the use of imprisonment, as opposed to cheaper forms of non-monetary sanctions, is quite puzzling. If there are two different punishment mechanisms that impose identical expected costs on convicts, yet one is cheaper for society to impose than the other, it seems that the cheaper one would always be preferable (D. Friedman 1999). Consider, for example, a five-year prison sentence. Surely, there is some level of corporal punishment ${ }^{1}$ (or probability of execution) that is equivalently unpleasant (thus, providing the same level of deterrence) as a five-year

\footnotetext{
${ }^{1}$ Though, technically, corporal punishment includes imprisonment, in this paper I will use it to refer to nonimprisonment forms of corporal punishment (e.g. whipping or caning).
} 
prison sentence but would substantially cheaper. ${ }^{2}$ Why, then, do we continue to use imprisonment and almost never corporal punishment (the death penalty being the exception, and it is never used probabilistically to punish less severe crimes)? Could this possibly be optimal?

In a recent paper, David Friedman (1999) informally proposes an answer to this puzzle. ${ }^{3} \mathrm{He}$ argues that the policy makers who determine the magnitude of punishments for convicts do so to maximize their own utility function rather than that of a benevolent social planner. How this utility function weights the welfare of each member of society depends on the power or influence of the interest groups of which an individual is a member (he appeals to Becker's (1983) formal model of this situation). Because convicts have little or no power or influence, the policy maker gives them very little weight in his objective function. (Admittedly, there are groups that represent the interests of convicts, e.g, the ACLU or Amnesty International. As George Bush demonstrated in the 1988 presidential campaign, however, garnering the support of these groups, being a "card-carrying member of the ACLU," may do a politician more harm than good.) As a result, if punishing convicts were nearly costless, the policy maker would punish excessively. By increasing the cost of punishment to the rest of society, however, a social planner can induce the policy maker to choose punishments that are less excessive (though, given the cost, punishment magnitudes will still be socially excessive due to the reduced weight put on convict welfare). Imprisonment serves this function.

This justification necessarily assumes that while policy makers can say the penalty for robbery is 1 year or 5 years or 20 years in prison, the form of the punishment is constrained, perhaps by constitutional prohibition against cruel and unusual punishment. Thus, it is important to note that this is a normative, rather than a positive, analysis (hence, the title is "Justifying Imprisonment" rather than "Explaining Imprisonment”). That is, Friedman's hypothesis argues that constitutional or other constraints that force policy makers to use imprisonment rather than cheaper forms of corporal

\footnotetext{
${ }^{2}$ Posner (1985) argues that afflictive punishments that impose an equivalent disutility as a five-year prison sentence would be so severe as to risk death or permanently injure the convict. This does not explain, however, why such punishments are welfare-reducing vis-à-vis imprisonment. Moreover, convicts run these risks in prison as well.

${ }^{3}$ I informally discuss other possible answers to this puzzle, and why they are not totally convincing, in section II.
} 
punishment are optimal but does not explain why they exist. Of course, most other analysis of optimal punishments are normative in nature in that they justify why punishments should or should not be maximal or when monetary versus non-monetary sanctions are optimal.

This hypothesis, however, brings up several additional questions. Is it necessarily the case that the social benefit (for a social planner who weights all individuals equally) of more optimal punishment magnitudes is worth the added social cost of more costly punishment? Does our current use of imprisonment come at all close to balancing the costs of costly punishment with the benefit of more optimal punishment magnitudes? How much must the policy maker discount the welfare of convicts relative to the rest of society to make costly punishment optimal?

In this paper, I formally model Friedman's hypothesis and "solve" it via simulation to answer these questions, along with some others. In particular, I show that if the distribution of benefits from crime is uniform, then it is never optimal to impose costly punishment. For density functions, such as the normal or the logistic, that get very small for very large benefits of crime, however, costly punishment can be optimal when the policy maker (the agent who determines the magnitude of the punishment) discounts the utility of the convicts sufficiently. For parameter values that are roughly consistent with available data, costly punishment is almost certainly optimal when the weight the policy maker attaches to convicts is no larger than five percent of the weight he gives to victims. And costly punishment could be optimal when this weight is as high as 15 to 20 percent.

Given the lack of political power of convicts, it is probably reasonable to assume that their weight in the objective function of policy makers is substantially less than five percent. If this is in fact the case, just how costly should punishment be? For illustrative puposes, I consider the optimal punishment cost when the weight policy makers give to convicts is one percent of the weight given to everyone else. In this case, I show that the cost of punishment to society should optimally be somewhere between 5 percent and 25 percent of the cost to the convict (depending on the values of other parameters). Since that the average cost of imprisoning a convict for a year is about $\$ 20,100$ (Department of Justice 1995), the simulations in the paper suggest that current cost of punishment is probably not too far from the optimal level. In addition to validating our use of imprisonment in general, the simulations also justify the way 
prison conditions vary across offenses. I show that when costly punishment is optimal, the optimal cost is greater the less damaging the offense. Thus, while those convicted of lesser offenses should receive reduced punishments, the form of this reduction should not just be reduced time in prison but nicer prison conditions as well. This is consistent with current practice (Posner 1985), and (as I will discuss further below) inconsistent with the incapacitation theory of imprisonment.

In addition to Friedman's paper, there are a few other papers that discuss the effects of a selfinterested policy maker on optimal punishments. Garoupa and Klerman (2002) discuss how a rentseeking government will enforce the criminal law. This paper is primarily concerned with punishment by fines. Garoupa and Klerman (2001) consider how the possibility of corrupt enforcers affects the optimal use of non-monetary sanctions. While related in spirit, their paper assumes that non-monetary sanctions take the form of imprisonment and does not discuss the tradeoff between imprisonment and other forms of non-monetary sanctions. Most closely related is a paper by Hylton and Khanna (2001). This paper informally justifies pro-defendant criminal procedure as a means of constraining law enforcers and policymakers from using the criminal law to advance personal goals. They also mention Friedman's hypothesis that inefficient punishments can serve this end as well. Like the current paper, the focus of their analysis is normative, not positive, in that their analysis justifies these practices from a social welfare standpoint rather than explaining why they exist. Unlike my paper, however, they do not formally analyze under what circumstances (if ever) the benefits of inefficient punishments outweigh the costs.

The rest of the paper is organized as follows. Section II informally discusses some alternative explanations for why imprisonment might be superior to less costly forms of non-monetary sanctions. Section III describes the model of a social planner choosing the form of punishment knowing that a policy maker will then choose its magnitude. Section III also contains the analysis of the case of a uniform distribution of benefits from crime. Section IV explains how the simulations were done for the cases of a normal and a logistic distribution of gains from crime. Section V summarizes and discusses the results of the simulations. In Section VI, I discuss calibration issues raised in the simulations. Section VII concludes. Appendix A contains the proof of Proposition 1. Appendix B contains a more detailed description of how the simulations were done. 


\section{ALTERNATIVE EXPLANATIONS FOR IMPRISONMENT}

One reason for rigorously analyzing Friedman's hypothesis is that, while there are many other possible justifications for using imprisonment instead of cheaper forms of non-monetary sanctions, none of them provide a totally convincing justification for why it is almost never optimal to use other forms of non-monetary sanctions (other than capital punishment). One explanation is that we just do not have a taste for corporal punishment; society views it as inhumane or unfair (Miceli 1991 and Polinsky and Shavell 2000b discuss fairness and punishment). This, however, just assumes away the puzzle. Moreover, since corporal punishment need not impose any greater utility loss on the convict than imprisonment, why should a punishment that could make everyone (weakly) better off be viewed as inhumane or unfair?

Similarly, the fear of false positives cannot justify imprisonment since one could always use less severe corporal punishments. With false positives, however, imprisonment has the advantage that it is easier to reverse than corporal punishment if new information reveals that a convict is innocent. This certainly justifies using imprisonment and delaying corporal punishment until after all a defendant's appeals have been exhausted. The pro-defendant bias in our criminal justice system (Hylton and Khanna 2001), however, already greatly reduces the risk of false positives. In fact, as Hylton and Khanna (2001) demonstrate, it is already hard to justify this bias based solely on the risk of false convictions. Thus, it is seems unlikely that false convictions are both prevalent enough and likely enough to be reversed after many years in prison, that it is worth incarcerating huge numbers of convicts for long periods (at great expense) after they have exhausted all possible appeals based on the tiny probability that a conviction might be reversed (and, even then, there is no guarantee the freed convict is innocent). Certainly, this must be true for convicts that have been incarcerated for a great many years. In fact, for reversal of false convictions to justify imprisonment, it would also have to be the case that the social cost savings from ending a small number of prisoner's sentences early could not be more cheaply achieved by using corporal punishment and spending more resources on improving the accuracy of trials.

Some argue that prisons can serve to rehabilitate criminals. This must mean that time in prison either reduces the taste for crime or increases a prisoner's lawful opportunities. How effective 
rehabilitation is, ultimately, is an empirical question, though the high recidivism rate suggests that efforts at rehabilitation may not be worth the cost of imprisonment. This is not too surprising since by the time convicts are in prison, society has already incurred substantial expense (e.g., public schools) in the effort to make people value lawful behavior and enhance their lawful opportunities. Such efforts, before a person has already sunk a great deal of investment into crime-specific human capital, are likely to be more effective (though maybe not as well targeted) than prison rehabilitation. Even if rehabilitation is effective, it can justify imprisonment only if it is enough more effective than larger, cheaper, punishments are at reducing crime to justify its costs. Moreover, rehabilitation cannot justify very long prison terms that incarcerate convicts long after the point at which they are likely to commit more crimes.

A more convincing explanation is incapacitation. Even with corporal punishment, deterrence may be costly enough that we will not want to deter all crime (or, alternatively, there are some people who just are impossible to deter), so there will always be crime. By using imprisonment, we keep those criminals "off the street" so they cannot commit further crimes (see Shavell 1987b for a model of optimal incapacitation). Certainly, the incapacitation argument must be part of the explanation for the use of imprisonment, but it cannot be all of it. First, it is widely known that for many offenses (many violent crimes, for example), almost all offenders are relatively young. Yet, we still imprison people for such crimes past the age where there is any possibility they will commit such crimes in the future. Surely, there can be little, if any, incapacitation benefit to keeping a 75 year old convicted rapist in prison. Why not release him at 45 and make up the deterrence lost by adding in corporal punishment? Better yet, why not just release him at 45 and spend less money on prison amenities?

This brings up another reason why incapacitation cannot fully justify our punishment policies: we spend a great deal more money on prisons than is necessary to incapacitate criminals. One could claim that the optimal length of prison terms for incapacitation is greater than the length necessary for deterrence (when prison amenities are minimal), thus we have to spend money to meet both goals with the same sentence. This argument has two flaws. First, it is inconsistent with the fact that we often incapacitate convicts long past the point where there is any reasonable chance they will commit further crimes. Second, evidence indicates that increased prison terms reduce crimes primarily through 
deterrence for property crimes, while incapacitation is more important for violent crime (Levitt 1998).

This suggests that each year in prison for property crime should be more unpleasant than each year in prison for violent crime (since it is less necessary to increase prison amenities to balance incapacitation and deterrence affects for property crime). This is the exact opposite of current practice (Posner 1985). Thus, the extreme paucity of the use of corporal punishment for convicts along with the large amount spent on prison amenities still requires justification.

Moreover, in the United States, constitutional prohibition against cruel and unusual punishment (enforced by judiciary, the branch of government least subject to interest group influence) plays a key role in requiring such spending. Almost every state has been the defendant in at least one litigation alleging unconstitutional overcrowding (Levitt 1996). Because the simulations demonstrate that it can be optimal to force policy makers to use costly punishments, they provide an explanation for this constitutional intervention that incapacitation cannot.

\section{THE MODEL}

There is a population where each person can choose to commit a crime or not. If a person commits a crime she receives a benefit from doing so valued at $v$, where $v$ is drawn from a distribution with a cumulative distribution function $H$, with an associated probability density function $h$. For each crime that is committed, there is an exogenous probability, $\pi_{c}$, that someone will be caught and convicted for that crime. The person convicted for a crime, however, need not be guilty. The probability of being convicted of a crime as a result of committing it is given by $\pi_{n} \leq \pi_{c}$ (some convictions could be of innocent people). If convicted, a person is punished by a punishment amount $z$, where $z$ is measured in terms of the utility loss to the convict. When a convict is punished by $z$, this costs society an amount $\alpha z$.

The form of the punishment determines the value of $\alpha$. For example, the use of fines collected without cost would yield $\alpha=-1$, society gains from the punishment via the receipt of fines. Note, however, that I rule out the use of fines in this model (I require $a \geq 0$ ) since, as discussed above, there are already convincing explanation for why fines are not always optimal, and I want to analyze the optimality of imprisonment versus other forms of non-monetary sanctions. The fact that fines are sometimes used together with costly punishment, however, is not inconsistent with the claim that costly punishment may 
be preferable to costless punishment. Because the social welfare function is non-linear (see below), the tradeoff between the greater cost of more costly punishment and its benefits in terms of reduced overpunishment need not be identical at all levels of punishment cost. (In fact, given that there is no social cost to excessive punishment with fines, since society gains exactly what the convict loses, the tradeoff is not an issue for fines.) For corporal punishment $\alpha$ will be near zero. For imprisonment, however, $\alpha$ will be (non-trivially) positive, and it will be larger the nicer the prison conditions. I assume that through combinations of corporal punishment and imprisonment or by varying prison conditions that there is a punishment form that corresponds to any (non-negative) magnitude for $a$ (that is, I assume that any $a \geq 0$ is in the feasible set for $a$ ).

Every person, then, will commit a crime if and only if $v>\pi_{n} z{ }^{4}$ Notice that the possibility of wrongful conviction has no direct impact on an individual's decision to commit a crime. Even if innocent people get convicted quite often, any given person is just one of a very large number of innocent people who could be wrongfully convicted, so any effect of wrongful conviction on the incentive to commit a crime will be extremely small. Moreover, as was pointed out by Schrag and Scotchmer (1994), crime opportunities can be either exclusive or non-exclusive. If a crime opportunity is exclusive, then if one does not commit this crime, no one will. Thus, not committing the crime does not increase one's probability of being wrongfully convicted of a crime.

In addition to this rational crime, however, I assume there is a fraction, $\kappa$, of the population that will commit a crime regardless of the costs or benefits (note, I allow these people to commit an additional crime if it is rational for them to do so, i.e. if $v>\pi_{n} z$ ). One can think of $\kappa$ as representing some combination of irrational and accidental criminals and people who are very insensitive to any sort of punishment. Of course, since one can set $\kappa=0$, the model does not require that such people exist. In the simulations below, however, I find that, without a positive $\kappa$, the generated crime rate is far below the actual United States crime rate and costly punishment is almost never optimal. Thus, although a small amount irrational or accidental crime or punishment insensitive people is necessary to justify costly punishment, it is also necessary to generate realistic crime rates. This is not surprising since without it the

\footnotetext{
${ }^{4}$ I assume that for each person there is only one crime that gives her this value $\mathrm{v}$.
} 
punishment magnitude could be set at infinity, deterring all crime without any concern for overpunishment since no punishment would ever be imposed. ${ }^{5}$ So long as the benefits from crime very rarely exceed the cost, this would be optimal (this point is related to that made by Kaplow (1990)). ${ }^{6}$ The total crime rate, then, is given by $\left((1-\kappa)\left(1-H\left(\pi_{n} z\right)+\kappa\right){ }^{7}\right.$ The harm from crime is given by a constant $d .{ }^{8}$

I assume that the magnitude of $z$ is chosen by a policy maker, who takes $\alpha$ as given, to maximize his objective function. The social planner chooses the form of the punishment, which determines $\alpha$, before the policy maker chooses $z$. Because I rule out fines, the social planner is restricted to punishment forms that generate non-negative $\alpha$. (Notice that I take the probability of conviction as given and ignore the social cost of obtaining it. Since the social cost of punishment is linear in magnitude, this assumption has no affect on the results. The policy maker will choose to increase the probability of conviction until the marginal cost of that equals the marginal cost of punishment, which is independent of the magnitude. Thus, the policy maker can sequentially optimize over the probability of conviction and then the

\footnotetext{
${ }^{5}$ One can also think of $\kappa$ as representing situations where society mistakenly believes a crime as been committed and thus punishes someone who could not have been deterred ex ante (because he did not commit a crime). Because the simulations below indicate $\kappa$ makes up the bulk of the crime rate, however, this interpretation is not very realistic. ${ }^{6}$ Of course, $\wedge>0$ also suggests that incapacitation must be an important reason for imprisonment. Nonetheless, as I argued in section II, it does not explain why we spend money on prison amenities or why we incarcerate people past the point where they are dangerous (Shavell 1987b).

${ }^{7}$ Notice that because undeterrable criminals can commit both a rational and an irrational crime, the crime rate could exceed 1 if no one is deterred from rational crime. While this poses no problem for the analysis, one could bound the crime rate at 1 by assuming that undeterrable criminals cannot commit a rational crime. This would make the crime rate $\left((1-\kappa)\left(1-H\left(\pi_{n} z\right)+\kappa\right)\right.$.

${ }^{8}$ The assumption that the harm from crime is constant is made for convenience, but for many crimes is probably roughly accurate. Even where it is not, one can think of $d$ as the average cost of a particular crime. Given that the criminal and the courts probably do not have much if any additional knowledge about the particular cost of crime to the victim, this assumption should not make any difference. The assumption that the benefits of crime vary is based on the idea that people's morality and opportunity costs vary, and it is justified by the fact that some people commit crimes while others do not.
} 
magnitude of punishment. Since the key variable of interest is the expected punishment (this paper is not about the tradeoff between probability and magnitude of punishment), there is no loss of generality by assuming an exogenous conviction rate.)

The social planner chooses $\alpha$, taking into account how this will affect the policy maker's choice of $z$, to maximize her objective function. Notice that the social planner acts as a Stackleberg leader in this game. One can think of the social planner as the one who sets up the constitutional restrictions on what is allowable punishment (e.g. ruling out cruel and unusual punishment, as in the United States). The objective functions of the social planner and the policy maker are as follows: ${ }^{9}$

$$
\begin{gathered}
U_{s p}=\int_{\pi_{n} f}^{B} v h(v) d v-\left(1-H\left(\pi_{n} z\right)+\kappa\right)\left[d+\pi_{c} z(1+\alpha)\right] \\
U_{p m}=\theta \int_{\pi_{n} f}^{B} v h(v) d v-\left(1-H\left(\pi_{n} z\right)+\kappa\right)\left[d+\pi_{c} z(\theta+\alpha)\right]
\end{gathered}
$$

The social planner weights the welfare of all citizens equally. Her objective function is split into two main terms, the benefits less the cost of crime per person. The first term represents the expected utility gain from crime, where $B$ is the maximum possible gain from crime (this could be infinite). The integral ranges from $\pi_{n} z$ to $B$ since only those whose benefits from crime exceed the expected sanction commit a (rational) crime. (I ignore any benefits received by those who commit "irrational" crimes, but this has no affect on the results since this just introduces a constant into the welfare function). The next term is the social cost of crime. As discussed above, $\left(1-H\left(\pi_{n} z\right)+\kappa\right)$ is the crime rate. Each crime creates a social loss of $d$ to the victim and a loss to the convict, if she is caught, which happens with probability $\pi_{c}$, of $z$. When punishment is costly, a convicted criminal also costs society $\alpha z$.

The policy maker's utility function is identical to that of the social planner's except that he only weights the gains and losses to the criminals and convicts by $\theta<1$. Notice that I am assuming that the policy maker applies this reduced weight to convicts even if they are innocent (though, this assumption is

\footnotetext{
${ }^{9}$ There is no term in either utility function reflecting any gain from irrational criminal activity. Since I assume irrational criminals are unaffected by punishment, this does not affect the results either here or in the simulations below.
} 
not critical to the analysis). As discussed in the introduction, this reduced weight is due to the fact that criminals and convicts (even innocent ones) have very little political power. They tend to be poor, disorganized, and not very politically active (felons typically lose the right to vote in the United States, though even with the right to vote, they still would probably have disproportionately little influence). Since the policy maker, unlike the social planner, cares about being re-elected, he gives the welfare of convicts and criminals very little weight.

For any given $\alpha$, the policy maker chooses $z$ to maximize $U_{p m}$. The first order condition for this maximization is given below: ${ }^{10}$

$$
-(\alpha+\theta) \pi_{c}\left(1-H\left(\pi_{n} z\right)+\kappa-\pi_{n} z h\left(\pi_{n} z\right)\right)+h\left(\pi_{n} z\right) \pi_{n}\left(d-\theta \pi_{n} z\right)=0
$$

The first term represents the policy maker's direct cost from punishing convicted defendants more, the second is the gain from falling crime rates. A marginal change in $z$ results in change in the total amount of punishment of $\pi_{c}\left(1-H\left(\pi_{n} z\right)+\kappa-\pi_{n} z h\left(\pi_{n} z\right)\right)$. Existing crimes, $1-H\left(\pi_{n} z\right)+\kappa$, are punished a little more, but the drop in crime results in a total loss in punishment for those crimes that are no longer committed, $\pi_{n} z h\left(\pi_{n} z\right)$. Of course, all of this punishment only occurs when a crime results in a conviction, which happens with probability $\pi_{c}$. The policy maker's marginal cost from an increase in punishment is $(\alpha+\theta)$ since extra punishment produces a social loss of $\alpha$ and costs the convict unity (since I measure punishment in terms of cost to the convict) whose welfare the policy maker weights by $\theta$. The policy maker's marginal gain from increased $z$ due to falling crime rates is $h\left(\pi_{n} z\right) \pi_{n}\left(d-\theta \pi_{n} z\right)$ because increasing $z$ reduces crime rates by $h\left(\pi_{n} z\right) \pi_{n}$. Reducing crime by one unit benefits the victim by an amount $d$, but it also eliminates the gain that the marginal criminal receives from crime, which is $\pi_{n} z$ since the marginal criminal is the one whose benefit from crime just equals expected punishment, which the policy maker weights by $\theta$.

\footnotetext{
${ }^{10}$ Whether the second order condition is satisfied will depend on the distribution for $h$. As Kaplow (1990) points out, corner solutions are not unreasonable. I explicitly address this issue below when I consider various distributions. At this point, I assume that the second order conditions are satisfied for expositional purposes. I do not make this assumption for any of the results below.
} 
Equation (3) implicitly defines a function $z^{*}(\alpha)$, the policy maker's optimal choice of $z$ given $\alpha$. The social planner, when maximizing (1), must take into account how her choice of $\alpha$ will affect the policy maker's choice of $z$. Thus, her first order condition for $\alpha$ is the following:

$$
\begin{gathered}
-\pi_{c} z^{*}(\alpha)\left(1-H\left(\pi_{n} z^{*}(\alpha)\right)+\kappa\right)+ \\
z^{* \prime}(\alpha)\left\{-(\alpha+1) \pi_{c}\left(1-H\left(\pi_{n} z *(\alpha)\right)+\kappa-\pi_{n} z *(\alpha) h\left(\pi_{n} z *(\alpha)\right)+\right.\right. \\
h\left(\pi_{n} z *(\alpha)\right) \pi_{n}\left(d-\pi_{n} z *(\alpha)\right\}=0
\end{gathered}
$$

The first line of (4) represents the direct effect of increasing $\alpha$, increasing the cost of punishment, which is always negative. The second two lines represent the affect of $\alpha$ on the policy maker's choice of $z$ times the marginal affect of $z$ on the policy maker's welfare. If $\theta=1$, the term in the curly brackets is identical to the policy maker's first order condition and thus is zero. It is only because $\theta<1$, the policy maker weights convicts' welfare less than does the social planner, that the curly bracket term is negative. When this inequality is satisfied, the social planner might want to make punishment more costly than necessary. By increasing $\alpha$, the social planner induces the policy maker to choose a smaller $z{ }^{11}$ At the margin, reducing $z$ increases social welfare due to the policy maker's incentive to over-punish. In general, there will be more than one $\alpha$ that solves (4). Since the social planner is restricted to $\alpha \geq 0$, however, costly punishment will increase social welfare if and only if the left-hand side of (4) is positive at $\alpha=0$. This is not necessarily the case. In fact, as Proposition 1 establishes, when the benefits of crime

${ }^{11}$ To verify that $z^{*^{\prime}}(\alpha)<0$ totally differentiate (3) with respect to $\alpha$ and solve for $z^{*^{\prime}}(\alpha)$ :

$$
z^{*^{\prime}}(\alpha)=\frac{\pi_{c}\left(1-H\left(\pi_{n} z\right)+\kappa-\pi_{n} z h\left(\pi_{n} z\right)\right)}{\pi_{n}\left\{(\alpha+\theta) \pi_{c}\left[2 h\left(\pi_{n} z\right)+\pi_{n} z h^{\prime}\left(\pi_{n} z\right)\right]+\pi_{n}\left[h^{\prime}\left(\pi_{n} z\right)\left(d-\theta \pi_{n} z\right)-h\left(\pi_{n} z\right) \theta\right]\right\}}
$$

The denominator is negative whenever (3) describes the policy maker's choice of $\mathrm{f}$ (it is the second order condition). While the policy maker's objective function will not be everywhere concave, for most distributions that are decreasing and very small at extreme values it should be concave at the optimal $z$ (the expected punishment should be large enough that $\mathrm{h}$ is very small and $\mathrm{h}^{\prime}$ is negative). The numerator is positive unless punishments are so high that even a policy maker who discounts the welfare of convicts relative to victims gains from rising crime rates, $d<\theta \pi_{n} z$. 
are uniformly distributed, the cost of costly punishment is always too great to justify the beneficial incentives it gives the policy maker unless the fraction of irrational criminals is quite large. And even then, costly punishment is never actually imposed since the policy maker chooses not to punish crime at all.

Proposition 1-When the benefits of crime are uniformly distributed between $A$ and B, the social planner always prefers costless to costly punishment, i.e. $\alpha>0$ is never optimal, unless $\kappa>\frac{\pi_{n}(d-B / 2)}{\pi_{c}(B-A)}$ and $A<0$ or $\kappa>\frac{\pi_{n}\left[d-\frac{A+B}{2}\right]}{B \pi_{c}}$ and $A \geq 0$. When costly punishment is optimal, the policy maker sets $z=0$, crimes are never punished.

When criminal benefits are uniformly distributed, increasing the punishment at any level deters the same number of crimes. The larger the punishment, however, the fewer convicts there are to punish, thus the lower the cost of imposing that punishment. Thus, the net benefit to a policy maker of increasing the punishment is increasing in the size of the punishment until that punishment is sufficient to deter all rational crime. As a result, the policy maker either sets the punishment high enough to deter all rational crime or does not punish crime at all, if the social cost of punishment, $(\alpha+\theta)$, is large enough (Kaplow (1990) was the first to point out that extremes of non-monetary punishment will often be optimal). Knowing this, the social planner has two options. She can set $\alpha=0$, inducing the policy maker to deter all crime at the lowest possible cost, or she can make $\alpha$ large enough that the policy maker does not punish at all (thus, the exact level of $\alpha$ does not matter). The former is optimal unless $\kappa$, the fraction of population that commits crimes regardless of the punishment, is quite large or difference between the harm from crime and the average benefit from crime is very small or the justice system does a very poor job of convicting the guilty party.

Also, notice that the level of $\kappa$ in Proposition 1 necessary to make costly punishment optimal increases as the judicial system gets more accurate, that is as $\pi_{n}$ apporaches $\pi_{c}$. The more accurate the 
judicial system, the less likely costly punishment will be optimal. In the simulations below, I show that this effect holds for other distributions of criminal benefits, but is quite small.

Proposition 1 demonstrates that if criminal benefits are uniformly distributed, Friedman's hypothesis cannot justify the actual imposition of costly punishment. With such a distribution, costly punishment is a very blunt an instrument. As a result, the social planner is will not to use it to influence the punishment magnitude decisions of the policy maker (unless it prefers that crime go unpunished). A uniform distribution of criminal benefits, however, is almost certainly not a reasonable description of any population. If the distribution of criminal benefits is declining above some point, then the policy maker's objective function will be concave in $z$ so long as $z$ is large enough. This makes an interior solution to the policy maker's choice of $z$ possible. When the solution to $z$ is interior, small changes in $\alpha$ will induce small changes in $z$. That is, costly punishment is no longer such a blunt instrument. Thus, it is possible that the social planner might want to make punishment more costly than necessary to influence the policy maker's choice of punishment. Unfortunately, for more realistic distributions of criminal benefits, it is not possible to solve the model analytically. Therefore, I use numerical simulations to study these cases.

\section{THE SIMULATIONS}

I perform two different types of simulations. The first set of simulations determine for what values of $\theta$ the social planner prefers a positive $\alpha$ to $\alpha=0$. That is, they answer the question: how much does the policy maker have to discount the welfare of convicts to induce the social planner to make punishment costly? In the second set, using a small value of $\theta$, the simulations determine how costly the social planner wants to make punishment for different parameter values. Thus, the goal of the second set of simulations is to determine possible optimal values of $\alpha$. In these simulations, I fix $\theta=.01$ to illustrate how costly punishment should be when difference between the policy maker's and the social planner's objective functions is close to its maximum. Appendix B explains how the simulations are done.

As much as possible, parameters for the simulations were chosen to accord with existing data on criminal activity and conviction rates in the United States. Where differences in the parameter values have a meaningful affect on the results, I did simulations for such a wide range of possible values that 
(where at least some calibration is possible) the range of results in the simulations provides reasonable bounds for the true values.

The Federal Bureau of Investigation (FBI) reports that the clearance rate for violent crime in the United States is 49 percent, and for property crimes it is 17 percent (Federal Bureau of Investigation 1999). The clearance rate is the percentage of offenses cleared by an arrest. Once charged with a crime, the conviction rate is about 60 percent for violent crimes and about 76 percent for property crimes (Department of Justice 1998c). Thus, .3 for violent crimes (.49(.6)) and about .13 for property crimes (.17(.76)) are reasonable values for $\pi_{c \cdot}{ }^{12}$ In all the simulations, I did one for $\pi_{c}=.3$ and one with $\pi_{c}=.13$. Not surprisingly given the first order conditions (see footnote 21) this difference did not make a difference in the results. Thus, all the results I report in Section IV will be for $\pi_{c}=.3$, the violent crime case.

How $\pi_{n}$, the net increase in the probability of being convicted of a crime when one commits a crime, will differ from $\pi_{c}$, the overall probability of being convicted of a crime, depends on the accuracy of the criminal justice system. Unfortunately, there is little data available on that issue. For the violent crime case, I looked at values of $\pi_{n}$ that varied from .297 (about one percent of all convicts are innocent) down to .230 (over 23 percent of all convicts are innocent).

The values for $\kappa$, the fraction of the population that commits a crime no matter how large the expected punishment is (I call these people irrational criminals), are also driven by criminal justice statistics. As mentioned earlier, a positive $\kappa$ is necessary for costly punishment to be optimal. Otherwise,

\footnotetext{
${ }^{12}$ Of course, these numbers are based on the number of offenses reported to the police. Since anywhere from a third to two-thirds of crimes are not reported to police (Department of Justice 1998c, Levitt 1998), these conviction probabilities are too small. That said, changes in the conviction probability, $\pi_{\mathrm{c}}$, will not significantly affect the results. By examining the policy maker's first order condition for $z$, one can see that so long as the relationship between $\pi_{\mathrm{c}}$ and $\pi_{\mathrm{n}}$ is fixed, changes in $\pi_{\mathrm{c}}$ will affect the size of $z$, but will not affect the size of the expected punishment, $\pi_{n} z$. By inspecting the social planner's first order condition, it is apparent that, so long as $\pi_{n} z^{*}(\alpha)$ is unchanged, changes in $\pi_{\mathrm{c}}$ (again, so long as it is a fixed multiple of $\pi_{\mathrm{n}}$ ) will not change the optimal $\alpha$. This intuition is confirmed by the simulation results for the two different values of $\pi_{\mathrm{c}}$ that were used.
} 
excessive punishments will never be imposed because the policy maker will set $z>B$, deterring all crime. So long as the number crimes with $v>d$ is small enough, the social loss from deterring efficient crimes will be dwarfed by the reduced punishment costs. With a positive $\kappa$, however, excessive punishments will be imposed, increasing the divergence between the social planner's and the policy maker's incentives. Thus, by choosing $\kappa$ so that the model generates an empirically reasonable crime rate, I can determine whether it is plausible that $\kappa$ could be large enough to justify costly punishment.

According to the FBI's Uniform Crime Reports, in the United States there are about 4.6 reported crimes per 100 people (Federal Bureau of Investigation 1999). This figure, however, is almost certainly an underestimate of the true figure, due to unreported crime and other factors, maybe by as much as a factor of three (Department of Justice 1998d; Dilulio 1996; Levitt 1998). Thus, the actual crime rate is probably somewhere between 8 and 14 percent. ${ }^{13}$ The model in this paper, however, generates a criminal rate rather than a crime rate. To get such an estimate, I use the fact that about five percent of the United States population will spend time in prison in their lifetime (Department of Justice 1998a). Of course, since people have more than one time in their lives to commit crimes, the actual number of criminals at any point in time must be well under five percent (assuming that almost all criminals spend time in prison at some point, though certainly not for every offense). If the criminal rate, then, is about one percent, this would imply that people have approximately five independent draws from the distribution that determines criminal activity in their lifetime (to generate the five percent imprisonment figure) and each criminal commits between 8 and 14 different crimes a year. While I have no data to support the first conjecture, there is some evidence that the second conjecture is roughly accurate. Prisoner surveys indicate that the median prisoner reports involvement in 12 to 15 crimes per year, though that number may overestimate the number of different crimes committed due to multiple perpetrators (Levitt 1998). Thus, a one percent criminal rate seems about right. In the simulations, it turns out that irrational criminals represent from 91

\footnotetext{
${ }^{13}$ Citing victimization surveys, Levitt (1998a) estimates that only $38 \%$ of crimes are reported, implying a crime rate of just over $12 \%$.
} 
to 99 percent of criminals. ${ }^{14}$ Thus, to get a criminal rate close to the actual one, I use $\kappa=.01$ in most of the simulations, though I also do many simulations with $\kappa=.005$ and .02 .

While having such a large fraction of criminals be irrational may seem implausible, it is equally implausible that it is optimal to set punishments so low that one percent of the population rationally decides to commit crimes. Of course, the current method of punishment, imprisonment, may be costly enough that deterring more crimes by increasing sentence length is not efficient. But this just gets us back to the puzzle of why we use a method of punishment so costly that it is optimal leave so many crimes undeterred? If Friedman's hypothesis is the answer to this puzzle, without contradicting the existence of high crime rates, a very large fraction of existing criminals (albeit a very small fraction of the population as a whole) must not be deterred by increases in the magnitude of punishment. ${ }^{15}$ This is not to suggest that these criminals are undeterrable. Surely, most of these people would not commit crimes if they faced execution with certainty. One (somewhat) plausible explanation for the existence of these criminals is that there are people who are so overconfident about their ability to escape apprehension or conviction ${ }^{16}$ that their estimate of the cost of crime is only trivially affected by increases in punishment.

\footnotetext{
${ }^{14}$ The fact that irrational criminals make up such a large fraction of the total criminal population does not mean that an economic model of punishment is inappropriate. The overwhelming majority of the population make the decision about whether to commit a crime or not based on a rational comparison of costs and benefits, thus punishment remains an important deterrent. Moreover, the agents deciding on the form and magnitude of punishment are rational actors.

${ }^{15}$ Almost any plausible explanation for the use of imprisonment, however, will require an explanation for why it is optimal to have high crime rates rather than supplement costly imprisonment with some cheaper punishments. Even the argument that humanitarian behavior has become more affordable as society has grown richer only explains why we use imprisonment rather than corporal punishment now but we did not in the past. It does not explain why we would prefer higher crime rates to some use of corporal punishment now that we have grown richer. In fact, for violent crime, one would expect that as health and life expectancies improve that preferences for less violent crime would grow stronger.

${ }^{16}$ The pervasiveness of overconfidence is a very well supported psychological phenomenon, see, for example, Debont and Thaler (1995).
} 
In the simulation results, the absolute amount for the $d$ parameter, the damages suffered by the victims of crime, affects the results only through its relationship with the distribution of criminal benefits. Therefore, even if I could estimate the true harm from crime, such an estimate is useless without a corresponding estimate of the distribution of benefits. Thus, I set the harm from crime so that a given fraction of crimes has benefits that exceeded the harm (I call these efficient crimes, though they are only efficient given no punishment). The three different values I looked at were harms such that one in 740 crimes are efficient (the lowest harm level), harms such that one in about 32,000 crimes are efficient (the medium harm level), and harms such that about one in 3.5 million crimes are efficient (the highest harm level). These numbers correspond to levels of $d$ that are three, four, and five standard deviations away from the mean benefit of crime when criminal benefits are normally distributed. Of course, any comparison of the benefits and harms from criminal activity are problematic since it requires interpersonal utility comparisons. That said, it is reasonable to assume that in some, albeit very small, fraction of crimes the criminal does gain more than the harm s/he causes. The three levels of efficient crimes I postulate are meant to capture points close to the reasonable extreme possibilities and a point in the middle. One can also think of these three points as representing different classes of crimes. The lowest harm level, or the highest fraction of efficient crimes, might be roughly appropriate for minor offenses. The highest harm level, or the lowest fraction of efficient crimes, might be appropriate for the most serious crimes. ${ }^{17}$

For the distribution of benefits from crime, I did simulations that used both a normal and a logistic distribution (which looks like the normal but with fatter tails). Given that there is no information on the potential gain from crime for those people do not commit crimes, and available information about

\footnotetext{
${ }^{17}$ While it might be hard to imagine that the gain from murder is ever greater than the harm, it is not impossible. Of course I have no data on the matter, but it seems plausible that maybe one out of every 3.5 million murders involves a case where the murder might save lives on balance. These murders may not be identifiable, even ex post, so there will be no legal rule that excuses them.
} 
the gains for those who do commit crimes is extremely incomplete, ${ }^{18} \mathrm{I}$ chose these two distributions because (in addition to being commonly used statistical distributions) both have the property that the density of criminal benefits falls as benefits increase when benefits exceed the mean (unlike the uniform distribution). Both of these distributions are uniquely defined by their mean and variance. I ran simulations with a variety of different mean and variance combinations for both the normal and logistic distributions. When $d$ is a fixed number of standard deviations away from the mean gain from crime, the results of the simulations for each distribution depend on mean and standard deviation of criminal benefits only through their ratio. For most specifications, simulations were done with the mean to standard deviation ratio varying from negative four to positive four. ${ }^{19}$

\section{RESULTS}

When the benefits of crime are distributed normally or logistically, a social planner will prefer to make punishment costly rather than costless so long as the policy maker's weighting of the welfare of convicts, $\theta$, is sufficiently small. Exactly how small $\theta$ has to be depends on the value of the other parameters in the model and whether criminal benefits are distributed according to the normal or logistic distribution.

For any given level of the other parameters, in both the normal and the logistic case, the cutoff level of $\theta$, which I will call $\hat{\theta}$, such that for all $\theta<\hat{\theta}$ costly punishment is optimal, is a decreasing function of the ratio of the mean gain from crime to its standard deviation. The reason for this is that this ratio measures the fraction of people who will not commit a crime even if there is no punishment. The more such people there are, i.e. the more standard deviations the mean gain from crime is below zero, the less costly it will be to deter crime, even with costly punishment.

\footnotetext{
${ }^{18}$ While there is some data on the cost of crime to victims, this doesn't tell us how the gain to the criminal differs from the loss to the victim. Even stolen goods are likely to be worth less to the criminal (stolen goods do not sell at retail price) than to the victim. Criminals also have unmeasured effort costs and some may even have psychic costs (or, maybe, benefits) from committing crimes.

${ }^{19}$ In the normal case, I sometimes had to limit the (negative) range of the mean-standard deviation ratio to ensure that on average crime is inefficient.
} 
The following table summarizes the information the simulations provide about the effect of various parameters and choice of criminal benefits distribution on how much the policy maker must discount the welfare of convicts, $\hat{\theta}$, and on the optimal cost of punishment, $\alpha$.

\section{Summary of Results}

\begin{tabular}{lll}
\hline & Critical Weight on Convict & Optimal Cost of Punishment, $\alpha$ \\
& Welfare, $\hat{\theta}$ & \\
\hline Mean-S.D. Ratio, $m / \sigma$ & Decreasing & Decreasing \\
Harm from Crime, $d$ & Decreasing & Decreasing \\
& Greater Effect at Smaller $m / \sigma$ & Greater Effect at Smaller $m / \sigma$ \\
Fraction of Irrational & Increasing & Increasing \\
Criminals, $\kappa$ & Greater Effect at Smaller $m / \sigma$ & Greater Effect at Smaller $m / \sigma$ \\
Normal rather than & Smaller for Larger $m / \sigma$ & Smaller for Larger $m / \sigma$ \\
Logistic Distribution & Larger for Smaller $m / \sigma$ & Larger for Smaller $m / \sigma$ \\
\hline
\end{tabular}

For any level of this mean-standard deviation ratio, $\hat{\theta}$ is larger the less harmful is crime (or, more precisely, the greater the fraction of efficient crimes). This is not surprising. The less harmful is crime the less welfare is lost from reduced deterrence. Since the reason the social planner might use costly punishment is to reduce the magnitude of the punishment chosen by the policy maker, costly punishment necessarily reduces deterrence, and increases crime. The less harmful this is, the smaller is this negative effect on social welfare.

Before presenting the figures depicting the results for specific simulations, I will make a few general comments about all the figures that I will present in this section. First, note that all parameters will take standard values in all the figures unless otherwise specified. The standard values are $\pi_{c}=.3, \pi_{n}=.297, \kappa=.01, d=m+5 \sigma$ (normal case) or $d=m+15.065 \sigma$ (logistic case), where $m$ is the mean gain from crime and $\sigma$ is the standard deviation. The harm from crime in the logistic case is far higher than in the normal case. This is to hold constant the fraction of efficient crimes (crimes where the 
criminal benefits more than the victim suffers). Thus, the three values of harm that I use for the logistic case are $d=m+15.065 \sigma, d=m+10.3601 \sigma$, and $d=m+6.60638 \sigma$. These correspond to the same number of efficient crimes, one in 3.5 million, 32,000, and 740 respectively, as do $d=m+5 \sigma, d=m+4 \sigma$, and $d=m+3 \sigma$ in the normal case. As mentioned above, in the normal case, the curves will not extend as far to the left, into the negative $m / \sigma$ range, to ensure that $d$ is positive. This may also occur in other instances because the simulations were unable to converge on a solution, usually this happened in the normal case when $m / \sigma$ was very small. Figure 1 presents the simulation results when the criminal benefits are normally distributed for the three different levels of damages from crime.

\section{\{Figure 1 Here\}}

When the mean value of crime is positive and the standard deviation low, the policy maker must give the welfare of convicts less than 10 percent of the weight he gives the welfare of victims for costly punishment to be optimal. When the mean gain from crime is negative, however, costly punishment can be optimal for much larger $\theta$, even greater than 15 percent, provided the standard deviation is quite small. Given the relative political power of convicts, it is hard to imagine that $\theta$ is anywhere near that large. Thus, particularly if the mean gain from crime is negative, ${ }^{20}$ these simulations provide support for Friedman's justification for costly punishment.

Changing the value of other parameters does not change the qualitative nature of the results. As discussed above, using a value for the conviction probability, $\pi_{c}$, that is more appropriate for property crime (or takes into account unreported crime better) has only a trivial affect on the results. Reducing the accuracy of the justice system, changing $\pi_{n}$ from .297 to .230 , increases $\hat{\theta}$, but, again, the affect is extremely small.

\footnotetext{
${ }^{20}$ The mean gain from crime will be negative when there is a common morality that is widely enough held that most people wouldn't commit a crime even if there is no possibility of punishment, or, at least, government imposed punishment. While for some relatively minor offenses, e.g. speeding, this is seems unlikely to be the case, for many other offenses (particularly more serious ones) it is not implausible. The mean gain from crime will also be negative for many crimes that require effort given that for many citizens that effort will have a high shadow price due to the value of their lawful opportunities (I thank Joel Schrag for pointing this out).
} 
As Figure 2 will demonstrate, however, $\hat{\theta}$ is larger when criminal benefits follow a logistic distribution (for any given fraction of efficient crimes) except when the mean-standard deviation ratio of criminal benefits becomes quite negative (between -1.5 and -2 ), at which point $\hat{\theta}$ is larger when criminal benefits are normally distributed. Of course, this comparison is somewhat problematic due to the fact that, although the fraction of efficient crimes is held constant when the distribution of criminal benefits is changed, the actual magnitude of the harm suffered by the victims is much larger in the logistic case than in the normal case.

\section{\{Figure 2 Here\}}

This relationship is due to two factors. First, for any given fraction of efficient crimes, the harm from crime is larger under the logistic distribution than under the normal. This induces the policy maker to choose much larger punishments under the logistic distribution. The larger the punishment, the larger is the wedge between the policy maker's view of welfare and the social planner's. Thus, costly punishment is more likely to be necessary with the logistic distribution. Second, the fraction of people who are deterred without punishment is higher in the logistic distribution when mean-standard deviation ratios are positive, and lower when they are negative. The first effect tends to make $\hat{\theta}$ larger when the logistic is used for any mean-standard deviation ratio. The second effect makes $\hat{\theta}$ larger for the logistic distribution when the mean-standard deviation ratio is positive and smaller when it is negative. The curves cross when the ratio is negative enough that the effects balance out.

The effect of changing $\kappa$, the fraction of irrational criminals, also has a significant effect. Doubling this fraction to .02 makes costly punishment socially optimal for higher values of $\theta$. Similarly, cutting $\kappa$ in half, to .005 , reduces $\hat{\theta}$. The reason that larger $\kappa$ makes costly punishment more likely to be optimal is that it increases the number of convicts who suffer from punishment but for whom punishment serves no deterrent purpose. This induces the social planner to prefer smaller punishments. It has this effect on the policy maker as well, but to a much smaller degree since he weighs the welfare of convicts so much less than does the social planner. Figure 3 demonstrates this effect in the normal case for the highest level of harm from crime (when one in 3.5 million crimes are efficient). 


\section{\{Figure 3 Here\}}

This figure (and other simulations omitted for space considerations) demonstrate that, when the mean-standard deviation ratio of criminal benefits is relatively large, changing the fraction of irrational criminals has a relatively minor effect on the maximum weight the policy maker can put on the welfare of convicts to make costly punishment optimal. When this ratio gets smaller and becomes negative, however, the effect of changing the fraction of irrational criminals can be quite substantial. This occurs because when a large fraction of the population is deterred without punishment, it is more important for the social planner to prevent excessive punishment of convicts for whom punishment serves no purpose relative to using punishment to deter crime. Moreover, when a larger fraction of the population is deterred without punishment, the less punishment will be used. So making punishment costly does not result in as large social costs. While the qualitative nature of the results is similar when the fraction of irrational criminals is as low at one in ten thousand, if one eliminates irrational criminals entirely costly punishment is never optimal for the reason mentioned earlier.

Now I turn to the question of exactly how costly should punishment be? In answering this question, I assume, for illustrative purposes only, that $\theta=.01$, that is, the policy maker weighs the welfare of convicts one percent as much as he weighs the welfare of everyone else. As one might expect after seeing the results of the above simulations, the optimal cost of punishment will vary with the meanstandard deviation ratio and with the fraction of efficient crimes and the fraction of irrational criminals. Also, as one might expect, changing the values of the other parameters does not have much effect. Figure 4 shows what the optimal cost of punishment, $\alpha$, should be for standard parameters as function of the mean-standard deviation ratio of criminal benefits when these are distributed logistically. (The effect of using a logistic distribution as opposed to a normal is very similar to the effect depicted in Figure 2.)

\{Figure 4 Here\}

The optimal cost of punishment ranges from a low of about six percent of the cost suffered by the convict, when the mean-standard deviation ratio is positive four, to a high of over 20 percent when this 
ratio is very negative. ${ }^{21}$ As in the $\hat{\theta}$ simulations, the greater the fraction of irrational criminals the more costly punishment should optimally be. This effect is also more pronounced at smaller mean-standard deviation ratios. Nonetheless, the optimal cost of punishment is fairly robust to changing the fraction of irrational criminals: increasing the fraction of irrational criminals by a factor of 4 at a mean-standard deviation ratio of -3 only increases the optimal cost of punishment by 75 percent. Granted, this change is large. But even such a dramatic change in the fraction of irrational criminals, at a mean-standard deviation level that makes the optimal punishment cost very sensitive to such a change, does not come close to changing the order of magnitude of the optimal cost of punishment.

The results from the simulations do more than justify the existence of costly punishment, such as imprisonment, they also provide some justification for way it is used in the United States. According to the Department of Justice, the average cost of imprisoning an inmate in a state prison in 1996 was roughly $\$ 20,100$ per year (Department of Justice 1998a). This is about 6 percent of $\$ 335,000$ and about 20 percent of $\$ 100,500$. Thus, if the $\$ 23,000$ figure represents the total social cost of punishment not borne by the convict, then loss in convict welfare from a year in jail must be somewhere between $\$ 100,500$ and $\$ 335,000$ for existing punishment to be optimally costly. To the extent that there is also some incapacitation benefit from imprisonment (that exceeds the external benefits the convict could provide if free, from employment, for example), the actual, non-convict borne, social cost of imprisonment is probably less than $\$ 20,000$, on the average. So the above range in the loss in convict welfare from a year's imprisonment is probably too high.

While the range of convict welfare loss from imprisonment necessary to make current imprisonment costs close to optimal is plausible, it certainly cannot be viewed as strong support for this theory of costly punishment. The way prison amenities vary across crimes, however, is consistent with the simulation results for the theory. The simulations demonstrate that punishment should be more costly the less damaging the crime. Property crimes such as theft or breaking and entering are far less harmful than violent crimes such as murder or rape. Thus, in addition to giving less severe criminals less severe

\footnotetext{
${ }^{21}$ While off the graph in Figure 8, the optimal $\alpha$ for the medium and small harm from crime are greater than .2 when the mean-standard deviation ratio is less than -3 .
} 
punishments (for deterrence reasons), the theory suggests that the reduction in punishment should not just take the form of shorter sentences, but rather nicer prison conditions combined with shorter terms.

This is in accord with reality since convicts punished for less severe crimes are usually sent to prisons with more amenities than are convicts punished for very serious crimes (Posner 1985). This is not to suggest that the total cost of incarcerating those convicted of less severe offenses is less than incarcerating more dangerous criminals. This difference in cost, however, is probably mostly due to the greater security needs associated with housing dangerous criminals (which is outside the model). What the model does explain, however, is why some portion of the savings from reduced security needs (in minimum security prisons) is used to reduce the punishment associated with spending a year in prison, necessitating longer prison terms to achieve a given level of deterrence. Moreover, given that deterrence is relatively more important than incapacitation in reducing crime for property crimes than it is for violent crimes (Levitt 1998), the incapacitation theory of imprisonment suggests exactly the opposite. That is, for those convicted of property crimes as opposed to violent crimes, the incapacitation theory would warrant much greater reductions in prison terms combined with fewer prison amenities, both because the offense is less severe and because the incapacitation effect of punishment is much less important relative to the deterrent effect.

\section{CALIBRATION}

While for many of the parameter values used in the simulations I have been able to choose them based on existing criminal justice statistics, for the fraction of efficient crimes and the distribution of criminal benefits there are no empirical facts to serve as benchmarks. I can, however, check what predictions the simulations make about the value of statistics that can be empirically observed or estimated. If the simulated value and the predicted value are close, this suggests that the functional forms and parameter values used in the simulations are reasonable. The one statistic for which I can make this comparison is deterrence elasticity. In the context of the simulations, deterrence elasticity is the 
percentage change in the crime rate per percentage change in the expected net punishment of criminals. ${ }^{22}$ Because there is no incapacitation in my model, the entire effect is due to deterrence.

In the context of empirical data, deterrence elasticity is the percentage change in crime that is due to deterrence per the percentage change in punishment. Because changing punishment often means changing the length of imprisonment, I need to distinguish between changes in the crime rate that are due to incapacitation and those that are due to deterrence. Recently, Levitt has estimated of the elasticity of violent crime with respect to imprisonment is about 0.4 , while for property crime it is about 0.3 (Levitt 1998). As mentioned above, these numbers include both incapacitation and deterrence effects. To separate out the deterrent effect, I use Levitt's (1998a) decomposition of the deterrent and incapacitation effects of punishment. In that paper, he finds no significant deterrent effect for murder or rape, that deterrence and incapacitation effects are about equal for robbery (though the incapacitation effect may be slightly larger), and that for aggravated assault and property crimes the deterrent effect dominates (accounting for 75 percent of the effect of arrest rates on crime for property crimes). Thus, for property crime, a reasonable point estimate for the deterrence elasticity is about 0.225 , while for violent crimes as a whole it is probably around 0.15 to 0.2 (with larger estimates for less serious violent crimes).

How do these estimates of actual deterrence elasticity compare with the estimates generated from the simulations? As Figure 5 shows, the estimates from the simulations are systematically lower than the point estimates derived from Levitt's two papers. However, these simulation results are well within a reasonable confidence interval around those estimates, particularly for a negative mean-standard deviation ratio.

\section{\{Figure 5 Here\}}

The solid line, representing one efficient crime in 3.5 million, can be thought of as measuring the deterrence elasticity for the most serious violent crimes. For such crimes the simulations suggest deterrence elasticity is between 0.05 and 0.09 , depending on the mean-standard deviation ratio. Given that the impact of deterrence relative to incapacitation is much smaller for these more serious violent

\footnotetext{
${ }^{22}$ Because some innocent people are convicted, I take into account the fact that one might get punished even if s/he does not commit a crime.
} 
crimes than for violent crimes in general (Levitt 1998), and that estimates of the overall elasticity of crime with respect to imprisonment is also smaller for the more serious violent crimes (Levitt 1996), the predictions from the simulations for the most serious crimes are roughly consistent with the available data. $^{23}$

For property crimes, one might think either the line representing the middle level of harm or the line representing the lowest level of harm best approximates the simulations' predictions for deterrence elasticity. Again, these are well below the point estimates derived from the two Levitt papers. However, it is important to point out that while Levitt's point estimate for the elasticity of property crime with respect to imprisonment is either 0.321 or 0.261 (depending on specification), the standard error of these estimates are 0.138 and 0.117 respectively (Levitt 1996). Thus, to obtain a prediction from the simulations that is within just one standard error of the derived estimates for deterrence elasticity for property crimes from Levitt's papers (ignoring the standard errors in the deterrence-incapacitation breakdown) I only need to get a deterrence elasticity of around 0.14 . Using the middle level of harm from crime, this requires a mean-standard deviation ratio of about -4 . Using the lowest level of harm from crime, deterrence elasticity is around 0.14 when the mean-standard deviation ratio is about -1.5 .

While it is not the case that actual estimates of deterrence elasticity are completely consistent with the predictions of the simulations, they are fairly close. Certainly, the available data on deterrence elasticity cannot invalidate the results of the simulations, especially if the mean gain from crime is negative.

\section{CONCLUSION}

Existing theories of criminal punishment cannot justify the widespread use of imprisonment rather than corporal punishment, prohibitions against cruel and unusual punishment, or the existence of costly amenities inside prisons. This paper models the newly promulgated, but unanalyzed, hypothesis of Friedman to determine if, and under what circumstances, it is capable of justifying these previously

\footnotetext{
${ }^{23}$ Though Levitt's (1996) point estimates for elasticity are significantly different from zero, the standard errors of these estimates are not small. So it is certainly the case that the predictions of the simulations for the most serious crimes are probably well within one standard error of the best estimate of deterrence elasticity for such crimes.
} 
puzzling phenomena. His hypothesis is that using more costly forms of punishments to deter crime, such as imprisonment, rather than cheaper forms of corporal punishment is necessary to prevent policy makers from excessively punishing convicts because they lack political influence. My model of this hypothesis can only be solved analytically for a uniform distribution of criminal benefits, for which the hypothesis fails to justify the use of imprisonment rather than corporal punishment. Simulations using a normal or logistic distribution of criminal benefits, however, demonstrate that the hypothesis can provide a reasonable explanation for these phenomena. Moreover, the use of simulations enables the model to explicitly determine how much policy makers must undervalue the welfare of convicts, due to their limited political power, in order for costly punishment to be welfare improving. For plausible parameter values based, where possible, on available criminal justice statistics, deliberately making punishment costly (even when this cost is not necessary for any other purpose) can improve social welfare so long as the policy maker gives the welfare of convicts anywhere from less than five to less than 15 percent the weight he gives the welfare of everyone else. Given their lack of political power, such a weight seems quite plausible.

The simulations also provide explicit estimates of exactly what the optimal cost of punishment is when policy makers put almost no weight on the welfare of convicts. Depending on parameter values and functional forms, the simulations suggest that the cost of punishment that is not borne by the convict should be anywhere from about six percent to about 20 percent of the cost of the punishment to the convict. As with the estimates above, much of the variation in these estimates is due to differences in the assumed mean-standard deviation ratio of criminal benefits. Higher estimates correspond to smaller (and negative) values for this ratio. Some of the variation, however, is also due to variation in the value of the harm from crime used in the simulations. This variation is consistent with observed punishment characteristics. The simulations suggest that less severe crime should be punished with more costly punishment. This justifies why convicts convicted of less serious crimes are not just punished with shorter prison terms, but also are incarcerated in prisons with more amenities.

While Friedman's hypothesis can jusfiy both the use of imprisonment itself and the way we use it in, it does not explain how this use of imprisonment came into being. Societies have no benevolent 
planner that sets up immutable rules that policy makers have to follow. In the United States one could view the Constitution as such a set of rules, though it certainly was not written and ratified completely outside of normal political pressures. Moreover, in the United States the replacement of corporal punishment by imprisonment actually occurred in the early 1800 s, some time after the Constitution was ratified (L. Friedman 1993). On the other hand, the great majority of reforms in prison conditions (making punishment more costly) were instigated by court decisions arguing that the conditions of the time constituted cruel and unusual punishment in violation of the Constitution (L. Friedman 1993). This is consistent with Friedman's hypothesis in that judges are less subject to political pressures than are legislatures. A further investigation of a positive, as opposed to a normative, explanation for the use of imprisonment is left to future research. 


\section{APPENDIX A}

Proof of Proposition 1. Let $v \sim U(A, B)$. Then for $v \in(A, B), h(v)=\frac{1}{B-A}$. With this definition, the policy maker's second order condition becomes:

$$
\frac{\pi_{n}}{B-A}\left\{2 \pi_{c} \alpha+\theta\left(2 \pi_{c}-\pi_{n}\right)\right\}
$$

For $\alpha>0$, (A1) is positive. So the policy maker will chooses $z=\frac{B}{\pi_{n}}$ or $z=0$. To induce the policy maker to choose $z=\frac{B}{\pi_{n}}$, the planner can do no better than set $\alpha=0$. To induce $z=0$, the planner needs to make $\alpha$ sufficiently positive. So show that this is possible, I evaluate (2) at each $z$ when $v$ is uniformly distributed:

$$
\begin{gathered}
U_{p m}\left(z=\frac{B}{\pi_{n}}\right)-U_{p m}(z=0)= \\
\frac{B(n+1)}{2 \pi_{n}(B-A)}\left\{\pi_{n}(2 d-B \theta)-2(\alpha+\theta) \kappa \pi_{c}(B-A)\right\}
\end{gathered}
$$

Equation (A2a) assumes that $A<0$. If $A>0$, then we have:

$$
\begin{gathered}
U_{p m}\left(z=\frac{B}{\pi_{n}}\right)-U_{p m}(z=0)= \\
\frac{n+1}{2 \pi_{n}}\left\{\pi_{n}[2 d-\theta(A+B)]-2 B \kappa \pi_{c}(\alpha+\theta)\right\}
\end{gathered}
$$

(A2a) and (A2b) are negative for large enough $\alpha$, and when $z=0$ there is no punishment, so the cost of punishment is irrelevant. Now I evaluate (1) at $z=\frac{B}{\pi_{n}}, \alpha=0$ and at $z=0$.

$$
\begin{gathered}
U_{s p}\left(z=\frac{B}{\pi_{n}}\right)-U_{s p}(z=0)= \\
\frac{B(n+1)}{2 \pi_{n}(B-A)}\left\{\pi_{n}(2 d-B)-2 \kappa \pi_{c}(B-A)\right\}
\end{gathered}
$$

Again, equation (A3a) is valid when $A<0$, otherwise we have: 


$$
\begin{gathered}
U_{s p}\left(z=\frac{B}{\pi_{n}}\right)-U_{s p}(z=0)= \\
\frac{n+1}{2 \pi_{n}}\left\{\pi_{n}[2 d-(A+B)]-2 B \kappa \pi_{c}\right\}
\end{gathered}
$$

The social planner will prefer to induce punishment if and only if:

$$
\kappa<\frac{\pi_{n}(d-B / 2)}{\pi_{c}(B-A)} \text { or } \kappa<\frac{\pi_{n}\left[d-\frac{A+B}{2}\right]}{B \pi_{c}}
$$

for $A<0$ and $A>0$, respectively. Q.E.D. 


\section{APPENDIX B}

The simulations were done using Mathematica. In the second set of simulations I used Mathematica to numerically find roots (using the secant method) to the first order condition equations for the policy maker, equation (3), and the social planner, equation (4). Of course, this method does not find all the roots of the two first order conditions, only the one closest (in some sense) to the starting values. As a check, I also had the simulations compute the value of the social planner's objective function at the solution and the value of this objective function when $\alpha=0$. So while I cannot guarantee that the simulations always found the global maximums subject to the constraint that $\alpha \geq 0$, I do know that they are always superior to the $\alpha=0$, or costless punishment, option. Moreover, I did try many of the simulations with different starting values and never came up with more than one solution that satisfied the constraints $\alpha \geq 0$ and $z \geq 0$.

In the first set of simulations, I assume that $\alpha=0$ and then solve the two first order conditions (for the policy maker, equation (3), and the social planner, equation (4)) for the values of $z$ and $\theta$. This gives the value of $\theta$ that will induce the social planner to choose $\alpha=0$. I used Mathematica to numerically find roots (using the secant method) to these equations using the parameter values described above. I then checked these solutions by verifying that the optimal $z$ is decreasing in $\theta$ and the effect of $\alpha$ on social welfare is decreasing in $\theta$. 
Figure 1

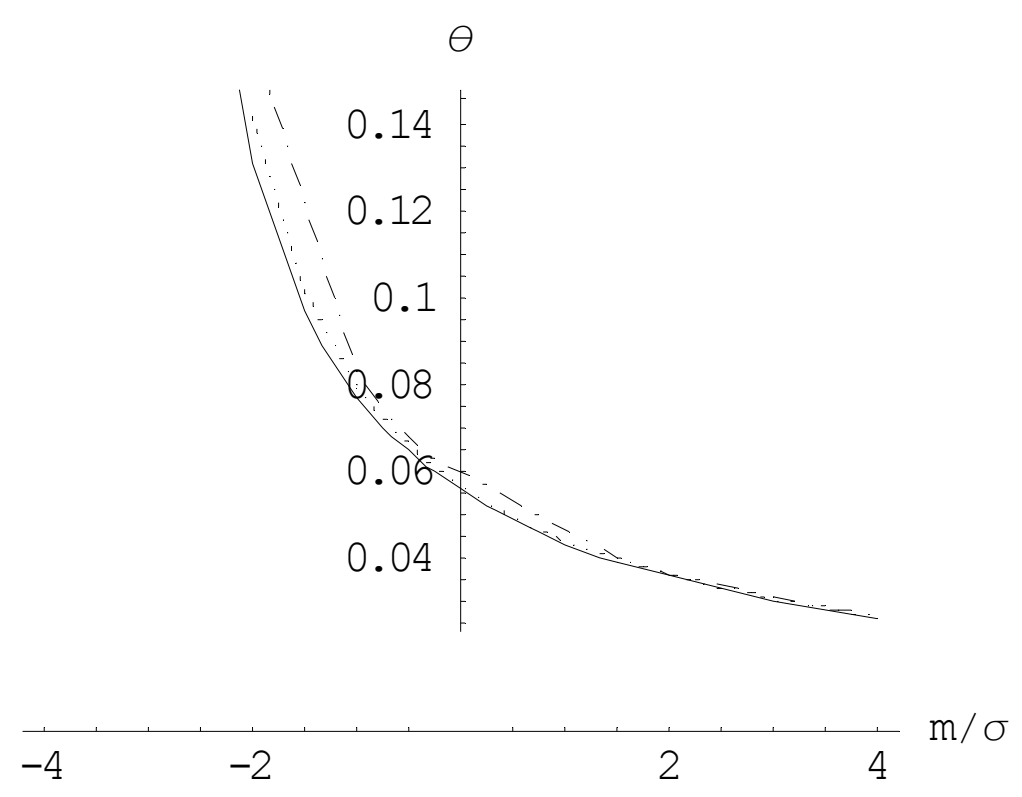

The solid line is the curve for $\mathrm{d}=\mathrm{m}+5 \sigma$, the dotted line is for $\mathrm{d}=\mathrm{m}+4 \sigma$ and the dashed and dotted line is for $\mathrm{d}=\mathrm{m}+3 \sigma$.

\section{Figure 2}

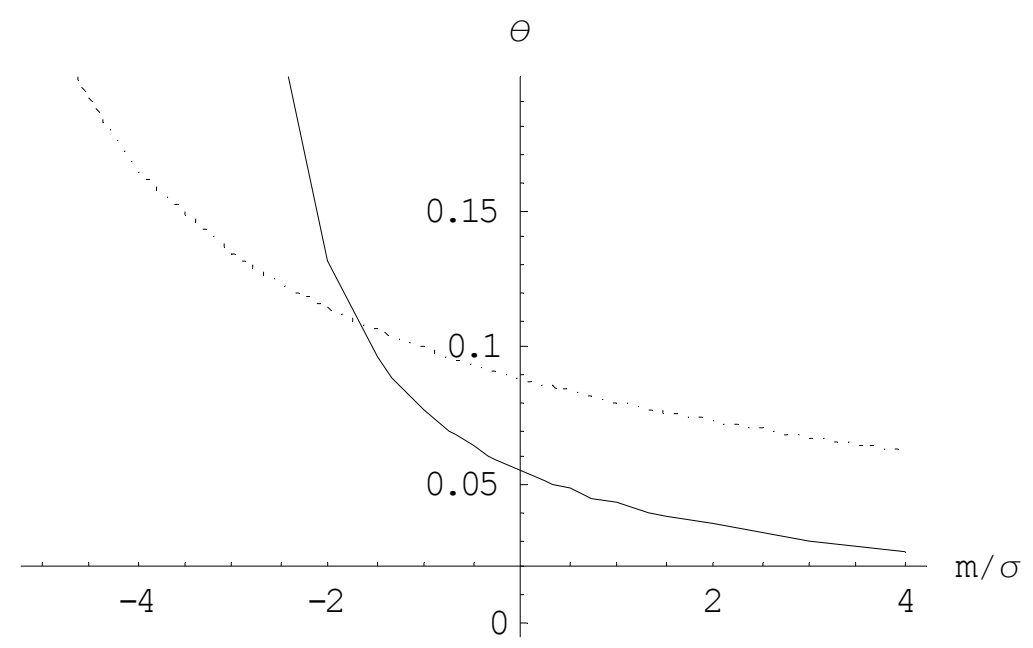

The solid line is for the normal distribution, the dotted line for the logistic. The parameter values are all standard. 
Figure 3

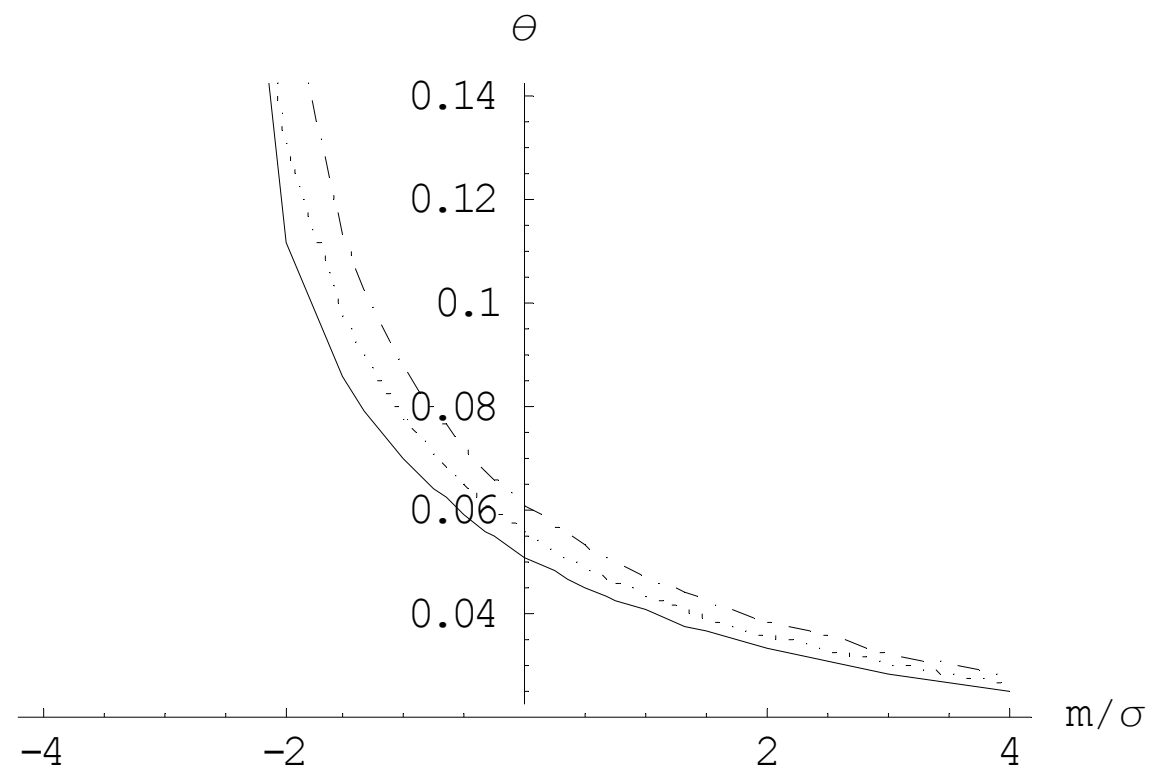

The solid line is the curve for $\kappa=.005$, the dotted line is for $\kappa=.01$ and the dashed and dotted line is for $\kappa=.02$. 
Figure 4

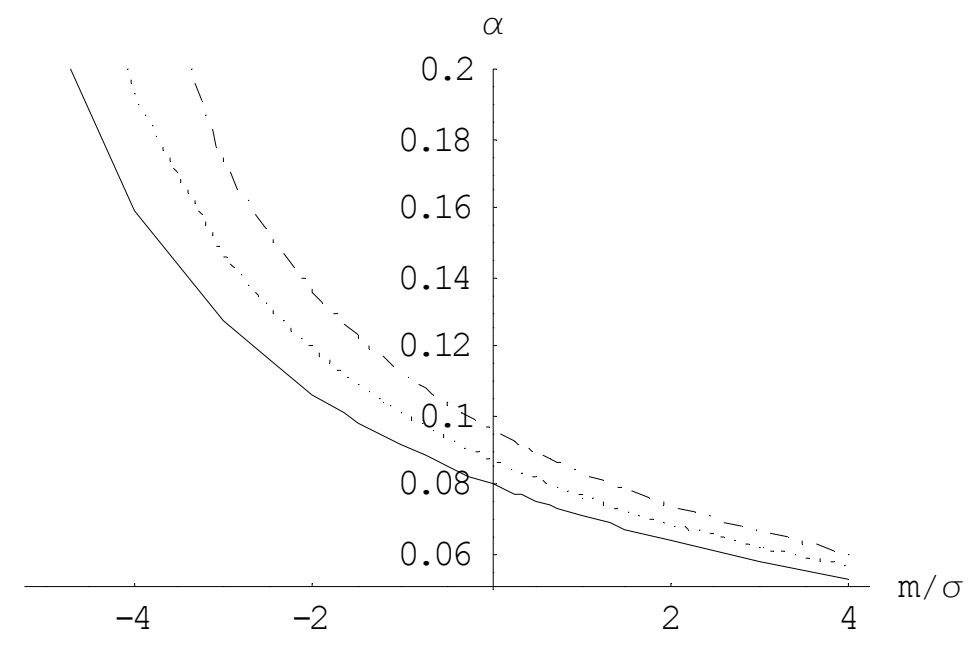

The solid line is the curve for $\kappa=.005$, the dotted line is for $\kappa=.01$ and the dashed and dotted line is for $\kappa=.02$.

Figure 5

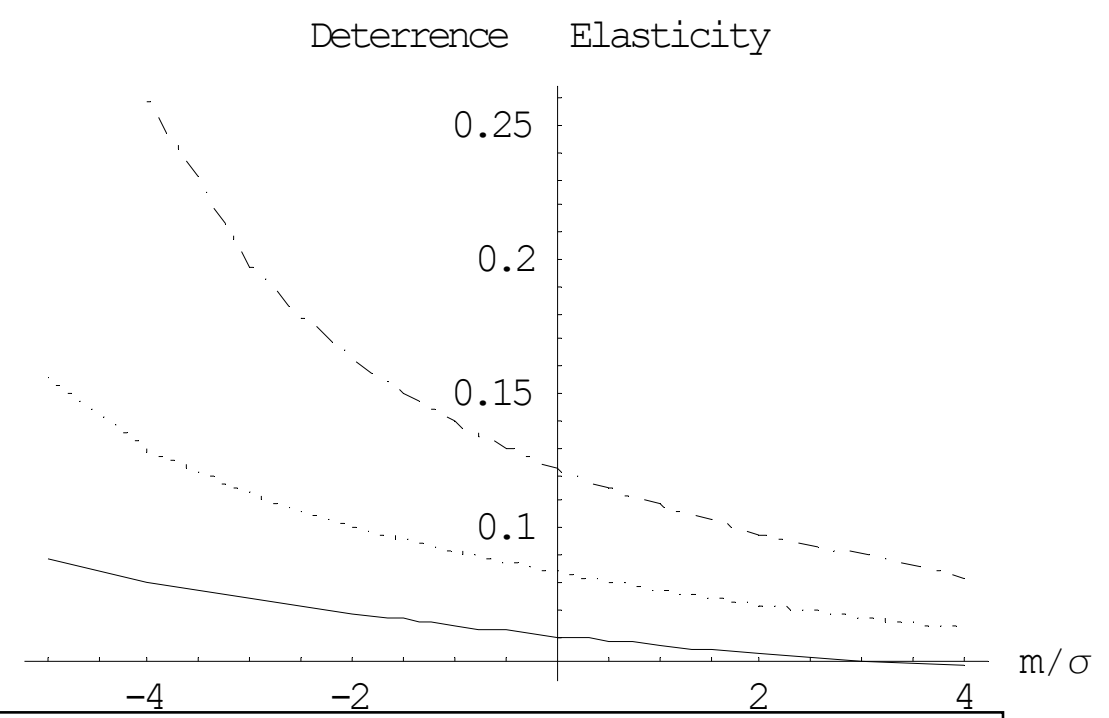

The solid line is the curve for $\mathrm{d}=\mathrm{m}+15.065 \sigma$, the dotted line is for $\mathrm{d}=\mathrm{m}+10.3601 \sigma$ and the dashed and dotted line is for $\mathrm{d}=\mathrm{m}+6.60638 \sigma$. 


\section{REFERENCES}

Becker, Gary S., "Crime and Punishment: An Economic Approach,” Journal of Political Economy, LXXVI (1968), 169-217.

, “A Theory of Competition among Pressure Groups for Political Influence," Quarterly Journal of Economics, XCVIII (1983), 371-400.

Chu, C.Y. Cyrus and Neville Jiang, “Are Fines More Efficient than Imprisonment?” Journal of Public Economics, 51 (1993), 391-413.

Debont, Werner F.M and Richard H. Thaler,. "Financial Decision Making in Markets and Firms: A Behavioral Perspective.” In Robert A. Jarrow, Voijslav Maksimovic, and William T. Ziemba, ed: Finance, Handbooks in Operations Research and Management Science, 1995, v. 9, ch. 13, p.385-410 (North Holland: Amsterdam).

Department of Justice, State Prison Expenditures, 1996 (Washington, DC: Department of Justice 1998a) , Bureau of Justice Statistics Fiscal Year 1998: At a Glance (Washington, DC: Department of Justice 1998b) , Sourcebook of Criminal Justice Statistics: 1998 (Washington, DC: Department of Justice 1998c) , Criminal Victimization in the United States, 1998 Statistical Tables, National Crime Victimization Survey (Washington, DC: Department of Justice 1998d)

_, Sourcebook of Criminal Justice Statistics: 1995 (Washington, DC: Department of Justice 1995)

Dilulio, John J. Jr., "Help Wanted: Economists, Crime, and Public Policy,” Journal of Economic Perspectives, X (1996), 3-24.

Ehrlich, Isaac, "Crime, Punishment, and the Market for Offenses," Journal of Economic Perspectives, X (1996), 43-67.

Federal Bureau of Investigation, Crime in the United States, 1998 Uniform Crime Reports (Washington, DC: Federal Bureau of Investigation 1999).

Friedman, David, "Why Not Hang Them All: The Virtues of Inefficient Punishment," Journal of Political Economy, CVII (1999), S259-S269.

Friedman, Lawrence M., Crime and Punishment in American History, New York, NY: Basic Books, 1993.

Garoupa, Nuno, “Optimal Magnitude and Probability of Fines,” European Economic Review, 45 (2001), $1765-1771$.

, “The Theory of Optimal Law Enforcement,” Journal of Economic Surveys, 11 (1997), 267-295.

, "Optimal Law Enforcement with a Rent-Seeking Government," American Law and Economics

Review, 4 (2002), 116-140. 
and Daniel Klerman, "Corruption and the Optimal Use of Non-Monetary Sanctions," SSRN, Working Paper Number 276117 (2001).

Hylton, Keith N. and Vikramaditya S. Khanna, "Toward and Economic Theory of Pro-Defendant Criminal Procedure," Harvard Law and Economics Discussion Paper, Number 318 (2001).

Kessler, Daniel and Steven D. Levitt, "Using Sentence Enhancements to Distinguish Between Deterrence and Incapacitation," Journal of Law and Economics, XLII (1999), 343-363.

Kaplow, Louis, "A Note on the Optimal Use of Non-Monetary Sanctions," Journal of Public Economics, 42 (1990), 245-247.

Levitt, Steven D., "The Effect of Prison Size on Crime Rates: Evidence from Prison Overcrowding Litigation," Quarterly Journal of Economics, CXI (1996), 319-51.

, "Incentive Compatibility Constraints as an Explanation for the Use of Prison Sentences Instead of Fines," International Review of Law and Economics, XVII (1997), 179-92.

, "Why Do Increased Arrest Rates Appear To Reduce Crime: Detreence, Incapacitaion, or Measurement Error?” Economic Inquiry, XXXVI (1998), 353-72.

Miceli, Thomas J., "Optimal Criminal Procedure: Fairness and Deterrence," International Review of Law and Economics, 11 (1991), 3-10.

, "Optimal Prosecutions of Defendants Whose Guilt is Uncertain," Journal of Law, Economics, and Organization, 6 (1990), 189-202.

Polinsky, A. Mitchell and Steven Shavell, "The Economic Theory of the Public Enforcement of Law," Journal of Economic Literature, 38 (2000a), 45-77.

,"The Fairness of Sanctions: Some Implications for Optimal Enforcement Policy," American Law and Economics Review, 2 (2000b), 223-237.

, “The Optimal Use of Imprisonment,” Journal of Public Economics, XXIV (1984), 89-99.

, "The Optimal Tradeoff Between the Probability and Magnitude of Fines," American Economic Review, LXIX (1979), 880-91.

Posner, Richard A., "An Economic Theory of the Criminal Law," Columbia Law Review, 85 (1985), 1193-1231.

Schrag, Joel and Suzanne Scotchmer, "Crime and Prejudice: The Use of Character Evidence in Criminal Trials," Journal of Law, Economics, and Organization, 10 (1994), 319-342.

Shavell, Steven, "The Optimal Use of Nonmonetary Sanctions as a Deterrent," American Econmic Review, 77 (1987a), 584-92.

, “A Model of Optimal Incapacitation," American Economic Review: Papers and Proceedings, 77 (1987b), 107-110.

, "Criminal Law and the Optimal Use of Nonmonetary Sanctions as a Deterrent," Columbia Law Review, 85 (1985), 1232-62. 